\title{
WEB MAPPING ARCHITECTURES BASED ON OPEN SPECIFICATIONS AND FREE AND OPEN SOURCE SOFTWARE IN THE WATER DOMAIN
}

\author{
C. Arias Muñoz ${ }^{\mathrm{a}, 1}$, M. A. Brovelli ${ }^{\mathrm{b}}$, C. E. Kilsedar ${ }^{\mathrm{b}}$, R. Moreno-Sanchez ${ }^{\mathrm{c}}$, D. Oxoli ${ }^{\mathrm{b}}$ \\ ${ }^{a}$ Faculty of Engineering, Universidad de San Buenaventura, Carrera 56C Nro. 51-90, Medellín 050010, Colombia - \\ carolina.arias@usbmed.edu.co \\ ${ }^{b}$ Department of Civil and Environmental Engineering, Politecnico di Milano, P.zza Leonardo da Vinci 32, 20133 Milan, Italy - \\ (maria.brovelli, candaneylul.kilsedar, daniele.oxoli)@polimi.it \\ ${ }^{c}$ Department of Geography and Environmental Sciences, University of Colorado Denver, Denver, CO, USA 80217 - \\ rafael.moreno@cudenver.edu
}

\section{Commission IV, WG IV/4}

KEY WORDS: Web Mapping, Water, Open Specifications, Free and Open Source Software (FOSS), Decision Support Systems, Content Management Systems

\begin{abstract}
:
The availability of water-related data and information across different geographical and jurisdictional scales is of critical importance for the conservation and management of water resources in the $21^{\text {st }}$ century. Today information assets are often found fragmented across multiple agencies that use incompatible data formats and procedures for data collection, storage, maintenance, analysis, and distribution. The growing adoption of Web mapping systems in the water domain is reducing the gap between data availability and its practical use and accessibility. Nevertheless, more attention must be given to the design and development of these systems to achieve high levels of interoperability and usability while fulfilling different end user informational needs. This paper first presents a brief overview of technologies used in the water domain, and then presents three examples of Web mapping architectures based on free and open source software (FOSS) and the use of open specifications (OS) that address different users' needs for data sharing, visualization, manipulation, scenario simulations, and map production. The purpose of the paper is to illustrate how the latest developments in OS for geospatial and water-related data collection, storage, and sharing, combined with the use of mature FOSS projects facilitate the creation of sophisticated interoperable Web-based information systems in the water domain.
\end{abstract}

\section{INTRODUCTION}

Water is fundamental to human life and the functioning of natural systems in the atmosphere, land surface, and underground. We are in an age when more often water resources are increasingly scarce or overly abundant, and the impacts of human activities on them are evident and ubiquitous. These problems do not respect administrative or political boundaries, and they must be addressed integrating information from multiple sources at multiple spatial, temporal, and jurisdictional/managerial scales. Communication, coordination, and data sharing are critical for addressing the water conservation and management issues of the 21 st century. However, different countries, provinces, local authorities, and agencies dealing with water resources have various organizational, sociocultural, economic, environmental and information technology (IT) contexts that raise challenges to the creation of information systems capable of integrating and distributing information across their areas of responsibility in an efficient and timely manner. Tight and disparate financial resources, dissimilar IT infrastructures (data, hardware, software and personnel expertise) with different levels of use and commitment to close/private software solutions further complicate the creation of these systems.

The lack of standard formats and procedures has significantly limited the availability of information and capability to respond, for example to a flood event promptly and to assess and prioritize post-event actions effectively. Today it is common to find the necessary data and information in different formats distributed and isolated across multiple agencies (each with different geographical areas of responsibility) making its integration and analysis extremely difficult or impossible during the different phases of an event such as flood mitigation, preparedness, response, and post-event recovery.

There is a pressing need for interoperable water information systems that are user-friendly, easily accessible and capable of managing and sharing large volumes of spatial and non-spatial data. These systems must be based on well-tested principles and technologies with low access cost that facilitate scalability and long-term viability across jurisdictions and organizations. Geospatial capabilities for mapping, visualization, and spatial analysis will be necessary system components. Given the need for ubiquity, ease of access, flexibility and reduced risk of isolation and obsolesce, the World Wide Web is the platform of choice for the deployment of these systems (Moreno-Sanchez et al., 2007).

Web mapping is the process of designing, implementing, generating and delivering maps on the World Wide Web (Shekhar and Xiong, 2007), and it is also a unique term to label different kinds of applications that vary in terms of appearance, functionalities, and technologies used. The choice of a particular Web mapping system is driven by the system's purpose and the users' requirements.

We suggest that the capabilities and features characterizing free and open source software (FOSS), combined with the use of the

${ }^{1}$ Corresponding author 
latest open specifications (OS) for data integration and sharing over the Web, offer the functionality and capabilities necessary to address the challenges in creating distributed and interoperable Web Mapping systems required today in the water domain. To support this statement, the purpose of this paper is to provide examples of sophisticated mission critical Web mapping systems and their architectures based on the combined use of FOSS and OS. This information will help in educating managers and IT professionals on the features, advantages, and ways in which FOSS and OS can be used for the creation of interoperable Web-based applications and information systems in the water domain.

The paper is organized as follows: Section two presents an overview of current technologies and systems used in the water domain (Web-based and not Web-based). Section three presents a brief background on open specifications (OS) and free and open source software (FOSS) related to the water domain, and section four presents case studies describing architectures based on the use of OS and FOSS for the creation of Web mapping systems currently under development in the Politecnico di Milano, Italy. Section five presents some concluding remarks.

\section{OVERVIEW OF INFORMATION TECHNOLOGIES IN THE WATER DOMAIN}

Water resources studies and activities can be classified into the following domains (Johnson, 2008; Loucks et al., 2005): a) surface water hydrology, b) groundwater hydrology, c) water supply for municipalities, d) wastewater and stormwater, e) flood risk management and response, f) water quality, g) monitoring and warning, h) river basins, i) reservoir and irrigation systems management, and $\mathrm{j}$ ) hydro-electrical power generation. This classification is somewhat arbitrary. However, procedures for water resources analysis and design within each domain have some commonalities on location, technologies, and governing institutions involved in management activities (Johnson, 2008). Tecnologies in the water domain normally involves network analysis, mobile data collection and observations management combined all together.

Multiple methods and sophisticated simulation and optimization tools are applied in the domain of water resources management (Loucks et al., 2005). More specifically, spatial analysis and modeling tools and their integration into water resources decision support systems are contributing to better assessments and management (Johnson, 2000; Vanrolleghem, 2011). For example, the widely used Geographic Information System (GIS) software ArcGIS offers the Arc Hydro ${ }^{\mathrm{TM}}$ suite of hydrological tools

(http://resources.arcgis.com/en/communities/hydro/01vn000000 0s000000.htm). Also, there are several FOSS hydrological tools and projects such as SWAT (http://swat.tamu.edu), the Open Hydrology Project (http://openhydrology.org), and Hydronumerics

(http://code.google.com/p/hydronumerics/downloads/list).

In the reservoirs and irrigation systems domain, refined models and tools have been developed for the analysis and management of lakes and reservoirs around the world (Jorgensen et al., 2005; Labadie, 2004). Geomatics and GIS tools have been developed for the assessment of water demands and supply alternatives, as well as for the analysis of pipe and canal distribution networks. For example, WaterGEMS ${ }^{\mathrm{TM}}$ and WaterCAD ${ }^{\mathrm{TM}}$ (https://www.bentley.com/en/products/product-line/hydraulicsand-hydrology-software/watergems https://www.bentley.com/en/products/product-line/hydraulics- and-hydrology-software/watercad) respectively use GIS and CAD systems as platforms to model and forecast water supply and demand and manage water distribution systems (Prins and Bodeaux, 2000; Wu, Z., Wang, R., Diaz, D., and Walski, 2003). Models such as the CropWat model from the United Nations Food and Agricultural Organization (http://www.fao.org/nr/water/infores_databases_cropwat.html) are integrated with GIS databases to estimate water demands based on soil types, climatological data, land use maps and expected crop areas (Al-Najar, 2011; Feng et al., 2007).

In Europe, GIS has been incorporated in the analysis and management of diverse aspects of river and lake basins (Vogt, 2002), including the estimation of irrigation water requirements (Wriedt et al., 2009), water pollution from agriculture at the continental level (Giupponi and Vladimirova, 2006) and for the management of irrigation systems (Todorovic and Steduto, 2003). Water resources decision support systems have been developed in Europe to address the semi-structured and unstructured decision problems that are common in this domain (Giupponi, 2007; Mysiak et al., 2005).

GIS is extensively used in the domain of flood risk management and response. For example, hydrodynamic flood models have been connected to GIS to provide easy access and visualization of flood scenarios and impacts to disaster managers (Zerger and Wealands, 2004). In Europe, the European Floods Portal (http://climate-adapt.eea.europa.eu/metadata/portals/europeanfloods-portal-year-of-launch) provides access to floods risks and the Flood Alert System (EFAS) (Thielen et al., 2009) uses a Web GIS interface to explore flood reporting, forecasting, and alerts at the continental level. Some decision support products have been developed based on the assembly of forecasts from this system (Ramos et al., 2007). In Italy, the IDRA2d Hydraulic Subsystem IDRA2dH (http://www.pcn.minambiente.it/GN/en/software-eng/adbtoolbox-eng/cos-e-adb-toolbox-eng) was created by The National Geoportal for two-dimensional hydraulic modeling, delimitation of potential flood areas, flow velocity assessment, and to facilitate flood risk monitoring. Challenges and limitations remain in the use of GIS tools and data in flood risk assessment that relate to the incompatibility between resolution and scale of spatial data in spatial modeling environments and the resolution and scale of human spatial decision-making (Zerger, 2002). Also, challenges exist in the use of GIS in real-time disaster decision support and response that emerge from poor temporal detail of events as they unfold and non-GIS related impediments such as user access and knowledge (Zerger and Smith, 2003).

In the water resources domain, the possibility of migrating desktop-based algorithms to Web services have been tested (Díaz et al., 2007), not only for predicting flood areas (Auynirundronkool et al., 2012; Lanig et al., 2008; Müller et al., 2010; Walenciak et al., 2009), but also for water resources modeling in general (Feng et al., 2011). In the water resources domain, it is common to carry out time-consuming tasks for collecting, analyzing and processing large volumes of hydrological data through the use of traditional desktop GIS systems. Migrating to distributed Web services architectures in which multiple agencies manage their data and develop applications independently, and then make them available in an interoperable way can significantly improve the management and conservation of water resources, as well as response to flooding and other water-related events and emergencies. The following sections provide examples of how this can be achieved through the combined use of OS and FOSS for the capture, storage, and distribution of geospatial data over the Web. 


\section{OS, FOSS AND WEB MAPPING SYSTEMS}

This section presents first a brief background on developments in the area of OS in the water domain, and later relevant information about the characteristics of FOSS that make them appealing for the development of Web-based interoperable distributed systems in the water domain.

OS provide software engineers and developers information about a given specification as well as specific programming rules and advice for implementing the interfaces and protocols that enable interoperability between systems (Moreno-Sanchez, 2006). The Open Geospatial Consortium (http://www.opengeospatial.org) defines interoperability as "the ability for a system or its components to provide information portability and interapplication cooperative process control". Therefore, to fully accomplish interoperability, the choice of appropriate standards and technological tools is a fundamental requirement.

Implementation of OS as well as open data policies have to be supported by ad hoc software architectures. These architectures have to be designed to facilitate, on the one hand, end users reaching full control and replicability of their operations on data while, on the other, empowering service providers through easy to develop and maintain system components that facilitate maintenance and updating operations. This means interoperable software components, i.e. components that work with each other to overcome tedious batch conversion tasks, import/export obstacles, and distributed resource access barriers imposed by heterogeneous processing environments and heterogeneous data (OGC Glossary Interoperability definition http://www.opengeospatial.org/ogc/glossary/i). Among options to achieve these requirements, the use of FOSS has proven to be a promising alternative as we will illustrate in this paper.

FOSS are programs whose licenses give users the freedom to use them for any purpose, to modify them, and to freely redistribute them either the original or modified form without further limitations or royalty payments (Open Source Initiative http://www.opensource.org/docs/definition.php). FOSS has 2040 years of history (Lagesse, 2002). Several authors tell the story of the FOSS movement, the issues involved in their development and use, and why some FOSS projects are successful (Bonaccorsi and Rossi, 2003; DiBona and Ockman, 1999; Raymond and Young, 2001). Some of these authors concentrate on studying how the complicated task of distributed software development has been successfully achieved by the FOSS community. This development philosophy and experience is extremely valuable and provides a framework for the distributed development of Web-based systems in the water domain like the ones presented in the case studies in this paper (section 4).

In this context, the deployment of monolithic Web mapping systems that incorporate all possible services in the water resource domain may produce unfavorable outcomes, both regarding cost-effectiveness, as well as usability for end-users. Therefore, scalability and long-term viability are fundamental features for the new generation of information systems in the water domain.

Some organizations have missions that only require them to perform some specific task while others have limited resources that force them to develop their information systems in an incremental modular way. The combined use of FOSS and OS can assist these organizations in prototyping and testing components, and different aspects of a Web-based distributed information infrastructure at low cost and without the risks associated with the long-term commitments required by private and closed software (Moreno-Sanchez et al., 2007). FOSS and OS are developed and maintained in a modular, incremental and distributed way. They facilitate the same approach for the development and maintenance of the systems created through their use. Their use also enhances flexibility, as several mature FOSS options can carry out each of the functions required to create an information system. The use of FOSS and compliance with OS also enhance the chances of an information infrastructure long-term viability (Moreno-Sanchez et al., 2007).

There are many FOSS that can be used to build Web mapping systems compliant with OS. Table 1 presents a list of the most used FOSS that can perform several functions in such systems. Developers can choose other alternatives based on their preferences, requirements, and knowledge. OS and mature FOSS are continuously developed, frequently updated, and are not likely to disappear (some have a history of more than 30 years). The development of FOSS knowledge and skills in water-related organizations is likely to contribute to buffering them against the impacts of a reduction in budgets or resources required for prototyping and development of new information systems. Moreover, such qualities of OS and FOSS make them appealing not only for building Web applications in the water domain but in various domains.

While OS and FOSS provide the framework to achieve interoperability, attention must be paid by the service providers in developing needs-oriented Web mapping systems that respond properly to usability requirements. According to Michell (2005) there are five main functions a Web mapping system can offer (listed in the order of complexity):

a) Visualization: visually assembly information about a location; geographical distribution of data, data comparisons, etc.

b) Sharing: share static (image maps) or interactive maps. This can include the use of Web services specifications (such as those from the OGC) to allow users visualize or manipulate data on a desktop GIS or other Web mapping systems.

c) Map production: to produce high quality visual products for printing purposes.

d) Creating and manipulating: creation of new features through the process known as digitalizing (drawing on the screen). The shape and position of the features can be also edited.

e) Analysis: this functionality is related to data processing that can go from data classification, spatial proximity calculation (hotspot analysis), statistical summary, to more complex and ad hoc algorithms.

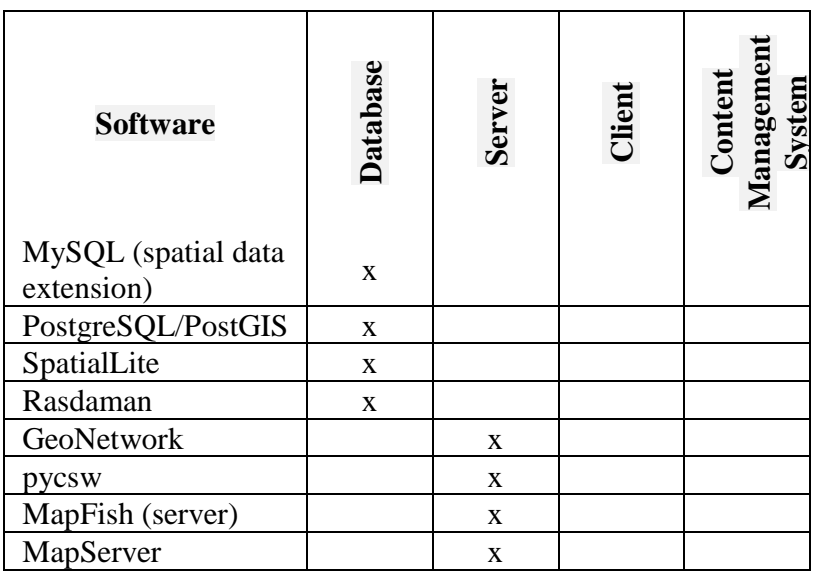




\begin{tabular}{|c|c|c|c|c|}
\hline Software & 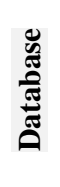 & 㐫 & 苞 & 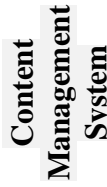 \\
\hline GeoServer & & $\mathrm{x}$ & & \\
\hline Deegree 3 & & $\mathrm{x}$ & & \\
\hline $52^{\circ}$ North & & $\mathrm{x}$ & & \\
\hline PyWPS & & $\mathrm{x}$ & & \\
\hline GeoNURIS & & $\mathrm{x}$ & & \\
\hline ZOO-Project & & $\mathrm{x}$ & & \\
\hline istSOS & & $\mathrm{x}$ & $\mathrm{x}$ & \\
\hline Geomajas & & $\mathrm{x}$ & & \\
\hline GeoMoose & & $\mathrm{x}$ & & \\
\hline Mapbender & & $\mathrm{x}$ & & \\
\hline Mapbuilder & & $\mathrm{x}$ & & \\
\hline Mapfish & & $\mathrm{x}$ & & \\
\hline $\begin{array}{l}\text { MapGuide Open } \\
\text { Source }\end{array}$ & & $\mathrm{x}$ & & \\
\hline QGIS Server & & $\mathrm{x}$ & & \\
\hline OpenLayers & & & $\mathrm{x}$ & \\
\hline Leaflet & & & $\mathrm{x}$ & \\
\hline MapFish (client) & & & $\mathrm{x}$ & \\
\hline Cesium & & & $\mathrm{x}$ & \\
\hline $\begin{array}{l}\text { NASA Web World } \\
\text { Wind }\end{array}$ & & & $\mathrm{x}$ & \\
\hline Marble & & & $\mathrm{x}$ & \\
\hline Drupal & & & & $\mathrm{x}$ \\
\hline Cartaro & & & & $\mathrm{x}$ \\
\hline GeoNode & & & & $\mathrm{x}$ \\
\hline easySDI & & & & $\mathrm{x}$ \\
\hline GeOrchestra & & & & $\mathrm{x}$ \\
\hline MapIgniter & & & & $\mathrm{x}$ \\
\hline CartoDB & & & & $\mathrm{x}$ \\
\hline
\end{tabular}

Table 1. Cutting-edge free and open source software to perform the role of the components in a Web mapping system

Web mapping systems can provide all or some of these functions depending on the user's requirements and expertise. Nevertheless, the new generation of Web mapping systems in the water domain should go beyond these basic functions. They should be capable of transforming data into useful information for better understanding and addressing water conservation and management problems such as water demand and supply, uncoordinated and disintegrated management of water reservoirs, irrigation deficit, as well as flood risks and damage assessments. The following section presents three case studies, which aim to address the challenges mentioned above by integrating into the system design process all the underlined considerations regarding interoperability, modularity, and embedding of functionality tailored for specific end users.

\section{CASE STUDIES}

We present here some experiences of the authors in the development of a Web mapping system in the water domain. The system architectures shown in this section use some of the most mature, reliable, and easiest to learn FOSS. There are numerous resources to learn these FOSS, and there are multiple examples of their application that can be used as prototypes for the development of new applications. These FOSS provide easy access to preset functionality that significantly speeds up development and reduces the need for advanced programming skills, thus empowering a broader audience of potential developers of systems like the ones here proposed.

The study case applications presented next address the following needs: a) the dissemination of water-related information at an urban scale, b) the integrated water resource management at a basin scale, and c) the collection, mapping, and evaluation of post-flood damage data.

\subsection{Buried Rivers}

This study case exemplifies the deployment of visualization capabilities in a Web-based system using FOSS. One of the main environmental drawbacks of urbanization processes is the the land cover or land use change within watersheds which in turn causes the increase of the soil imperviousness. As a consequence, the surface runoff in the watersheds is expected to increase, and hence, channels have to be able to cope with higher flow rates than the ones for which they were originally designed. Several flood cases in Italy can be traced back to the inadequacy of hydraulic works as well as to extensive land cover or land use changes that have negatively impacted watercourses (Brovelli et al., 2016).

The case of the city of Como in northern Italy can be considered as a perfect small-scale example of how urbanization impacts the natural environment. One of the most important impacts has been the burying of several natural watercourses under the city's road network. GIS technologies were used to digitize, store, manage, and analyze geospatial data from different historical periods in the development of the city of Como. Historical cadastral paper maps dating back to $17^{\text {th }}$ century were scanned and georeferenced, which allowed to trace the evolution of the city setting and the original location of the natural watercourses. The purpose of this study was to quantify the changes in the watercourses' peak flood discharges, as a consequence of the watershed urbanization. The calculated peak flood discharges were used for running water profile simulations that identify changes of the residual conveyance that occurrs in the buried channels.

Besides the hydraulic and hydrological analyses, a Web application was developed to allow access to the most important data and results of the analyses, which can be useful for any of citizen or city manager. The use of the Web as a platform for distributing geospatial data and visualization was favored by the following reasons: a) it reaches a wide range of non-expert users located over a wide geographical area at a relatively low cost compared to the traditional printing and updating of paper maps, b) data can easily and quickly be updated independently of the platform used by diverse contributors to the data sets, and c) it allows interactive and dynamic data representation, as well as querying for specific data and information.

Due to the pure informative nature of the Web application, most of the data processing and analyses were carried out before publishing the data through the Web application. Besides the historical cadastral paper maps that were scanned and digitized, other layers including soil runoff capacity maps were derived from analyzing available land cover, land use and soiltype maps, as well as the hydrological network extracted from the Digital Terrain Model (DTM) of the area.

The Web application is based on a light client-server FOSS architecture (see Figure 1). On the server side, GeoServer (http://geoserver.org) is used within Apache Tomcat Web server (http://tomcat.apache.org). The preprocessed layers (i.e. historical cadastral maps, soil runoff capacity maps, hydrological 
network, etc.) are stored in a PostgreSQL database with PostGIS extension that serves the layers using OGC Web Map Service (WMS) for raster layers, or Web Feature Service (WFS) for vector layers together with proper styling rules. Basemaps are provided by using external providers such as OpenStreetMap (https://www.openstreetmap.org).

The application was developed for providing access to waterrelated information through thematic maps. Therefore, for this particular case study, there was no need for providing end users the access to advanced analytical operations or data. Hence, the development was focused on enabling a user-friendly data navigation on the client side, including attractive features such as the temporal navigation of the historical cadastral maps using sliding bars that bring up different maps as the slide is moved (see Figure 2). The client is based on the Leaflet JavaScript library (http://leafletjs.com) coupled with the jQuery library (https://jquery.com). Specific functionalities of the jQuery Mobile framework (https://jquerymobile.com) were used to improve the responsiveness of the system on mobile devices. The Web application developed in this project is accessible at http://geomobile.como.polimi.it/buriedtorrents.

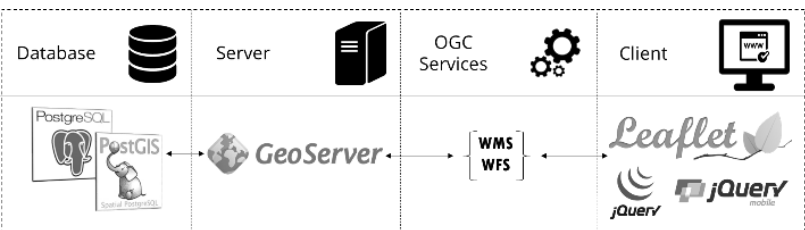

Figure 1. Buried Rivers system architecture

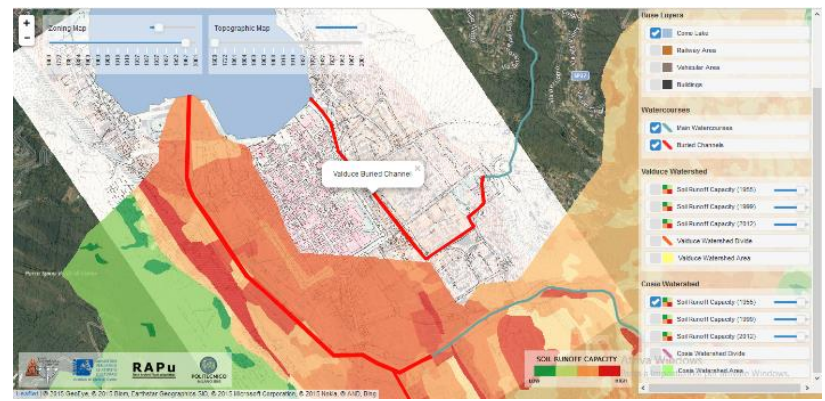

Figure 2. Buried Rivers user interface

The architecture described represents only one possible combination of FOSS for the creation of Web applications. Different components might be adopted according to the developer's needs and level of expertise. Nevertheless, the architecture includes all the basic components to implement an FOSS-based geospatial Web application compliant with OGC standards.

\subsection{Red-Thai Binh Rivers System Geoportal}

This case study exemplifies a Web-based system capable of manipulating, analyzing, and distributing geospatial data and model results. The Integrated Water Resource Management (IWRM) paradigm is defined by the Global Water Partnership (http://www.gwp.org/) as "a process which promotes the coordinated development and management of water, land and related resources to maximize the resultant economic and social welfare equitably without compromising the sustainability of vital ecosystems." Several institutions around the world such as the Water Framework Directive of the European Union and the United Nations have adopted the IWRM in recent years. Therefore, to support this paradigm, some tools, methods, and software have been developed specifically for system modeling, and for alternative design and evaluation (Soncini-Sessa et al., 2007).

The Red-Thai Binh Rivers System has a watershed that is divided between China and Vietnam. The river flows through 25 provinces in North Vietnam, including the capital Hanoi, affecting a population of 26 million people and feeding a network of canals that supplies water for nearly 1.1 million hectares of agricultural lands. In the Vietnamese part of the watershed, four large multipurpose reservoirs are in operation, which are used for hydropower production, flood control, navigation and water supply. The Integrated and sustainable water Management of Red-Thai Binh Rivers System in changing climate (IMRR) project (http://xake.elet.polimi.it/mediawiki/index.php) aims at developing and promoting strategies for the sustainable management of Red-Thai Binh Rivers System (hereafter denoted as Red Rivers System) in Vietnam through coordinated decisionmaking and negotiation, supported by water flow modelling and optimization tools, and through capacity building of local authorities in the water sector. To facilitate this process, a Web mapping system (geoportal) was created to visualize, analyze, and compare different planning alternatives in the context of the IWRM methodology and the IMRR project for the management of the Red Rivers System in Vietnam (see Figure 4).

To assess the impacts of changes in the Red Rivers System, a mathematical model of the system was created reproducing water flows from upstream catchments down to the river delta region. This model also considers the behavior of the components of the system (e.g. reservoirs, catchments, canal pumps, dams, etc.) and the relationships among them. Different water management alternatives can be simulated in the model, and it is also capable of analyzing climate change scenarios. For example, different reservoir regulation policies (e.g. upstream reservoir releases) can create different sets of water levels in a downstream reservoir The regulation policies (alternatives) can be compared using a set of indicators (e.g. maximum consecutive days of flood, maximum water level). Then, through a process of normalization and translation of the indicators' values, it is possible to compare multiple water regulation alternatives. The geoportal provides data that are the time series datasets of the state, input, output of the model variables that come from the different components the Red Rivers System located throughout the river watershed.

The geoportal has two distinct types of users: the common user or stakeholder, and the advanced user or analyst. Two different types of users have different permissions and can access different features on the geoportal: stakeholders can access basic functionalities such as data visualization in the form of maps or charts, while analysts can access more complex functionalities such as mathematical models and simulations.

The geoportal is based on a client-server FOSS architecture similar to the Buried Rivers Web application (see Figure 3). The main difference is the use of the istSOS server (http://istsos.org/), which allows the managing and dispatching of the time series observations from monitoring sensors and other system components according to the OGC Sensor Observation Service (SOS) standard. istSOS also connects to the PostgreSQL database using a distinct data schema for each scenario considered in the project. The client side is based on the Drupal Content Management System (https://www.drupal.org/), taking advantage of existing GeoServer and OpenLayers modules similar to those found in the Cartaro distribution (http://cartaro.org/). Two new modules for Drupal were developed: 
a) A general use module to connect istSOS and Drupal and to manage multiple time series and different scenarios inside

Drupal (https://www.drupal.org/sandbox/istsos/2149739).

b) A project-customized module, to manage interaction between maps, pop-ups, time series charts, and search functionalities.

These modules allow the interaction of different software components within the Drupal application without the need to launch them independently, because all their main features are available through a user-friendly interface.

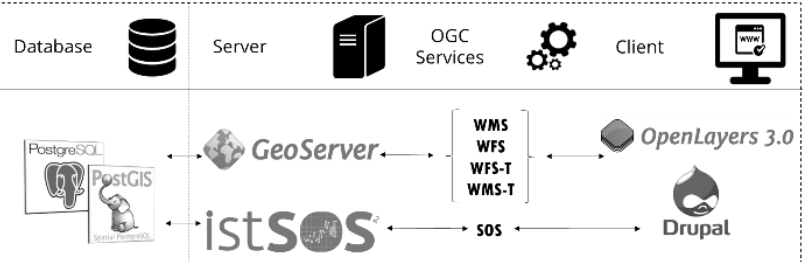

Figure 3. Red-Thai Binh rivers system geoportal architecture

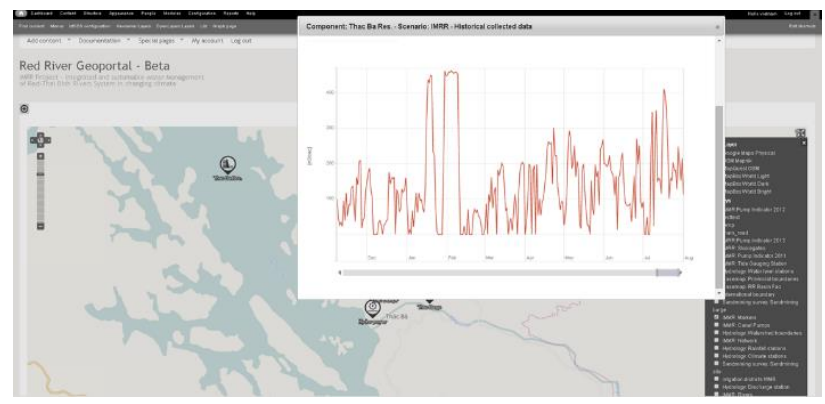

Figure 4. Red-Thai Binh rivers geoportal user interface

The geoportal is characterized by its efficient and non-technical approach to the access, operation, and distribution of the project's geospatial data. Currently, the simulations in the geoportal are being tested and improved.

\subsection{The Poli-RISPOSTA Web mapping system}

This case study exemplifies a Web-based system designed to provide visualization, data sharing, and map production capabilities. Numerous research efforts have been done on data collection for flood risk management. However, to date, there are no effective methods for estimating post-flood damage (Merz et al., 2010). As financial resources have become scarcer, the precise estimation of economic flood damage to define appropriate victims' monetary compensation and the prioritization of the necessary interventions has become more important than ever. Today flood risk management has become the main approach to flood control policies in Europe (Begum et al. 2007; European Commission 2007).

To measure effectively the direct and indirect flood damages, it is necessary to create a complete picture of the flood event that includes the physical triggers of the event, as well as the exposure and vulnerability of assets and infrastructure. To achieve this task, there is a need for better geographic data collection to provide scientists and stakeholders in the affected areas with reliable flood damage data. At the national and international levels, there are few experiences on the required interdisciplinary efforts for defining the methods, tools, and procedures to generate the information essential for post-emergency operators and the scientific community.
The Poli-RISPOSTA ("stRumentI per la protezione civile a Supporto delle POpolazioni nel poST Alluvione ", which can be translated as "civil protection tools to support the community affected by floods in the post-event") project aimed at creating tools for the collection, mapping, and evaluation of post-flood damage data (https://polirisposta.wordpress.com/). This information is essential for all organizations involved in flood risk management. This project involves the testing of tools and procedures for the integration of an interoperable Web-based system, as well as the development of capabilities to collect and deliver information to mobile devices in the field for civil protection volunteers. This work is expected to support communities in the post-emergency phase, and it will contribute to promoting a risk management culture in areas susceptible to flood risks.

The Poli-RISPOSTA Web portal is focused on data sharing and geospatial data visualization. Regarding data sharing it allows uploading and downloading statistical reports and reports of damages to vital utilities (e.g. railroads, electricity lines, industrial buildings, residential buildings, public infrastructures, public spaces, etc.), and printing of map layers (see Figure 6).

The architecture of the system is shown in Figure 5. One distinct characteristic of this architecture is the inclusion of mobile technologies for data collection on the field, by an ad hoc Android mobile application based on Django, Java, and SQLite. A big part of the architecture is based on the GeoNode open source geospatial content management system (http://geonode.org/), a platform that facilitates the creation, sharing and collaborative use of geospatial data. GeoNode core is based on Django Web framework with a few more dependencies necessary for the communication with the geospatial servers that are part of Poli-RISPOSTA (GeoServer for the OGC Web services and pycsw for the catalog and metadata service). The mapping functionality is based on GeoExplorer (http://suite.opengeo.org/opengeodocs/geoexplorer/), enriched with GeoExt (http://geoext.org/) and Ext JS https://en.wikipedia.org/wiki/Ext_JS).

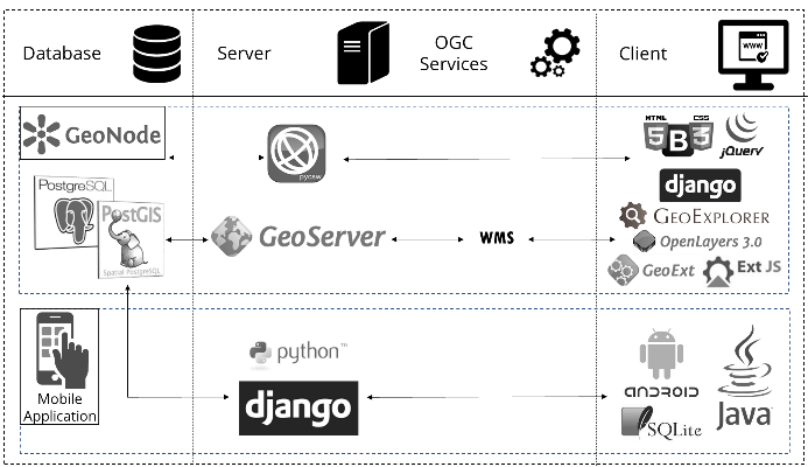

Figure 5. Poli-RISPOSTA system architecture 


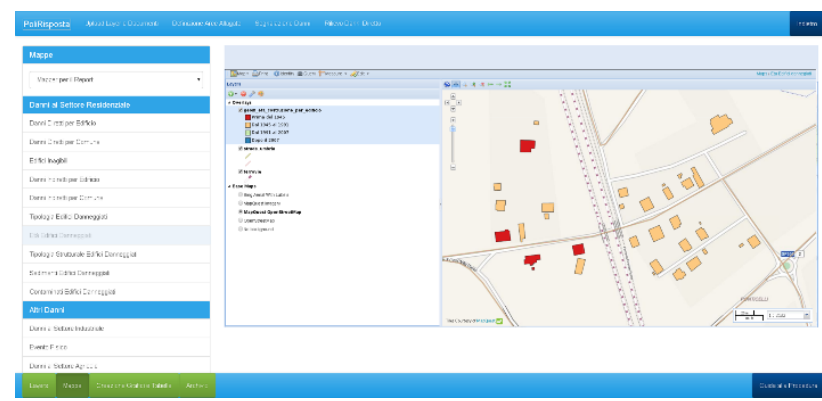

Figure 6. Poli-RISPOSTA Web portal user interface

The architecture shown in Figure 5 is an example of how FOSS can be used in an area of disaster recovery to obtain and distribute the data required to support the assessment of damages and decision-making regarding post-disaster planning.

\section{CONCLUSIONS}

In this paper, we illustrate the role that OS and FOSS can play in developing efficient and low-cost software architectures for creating Web mapping systems in the water domain. The case studies described are real cases that address critical aspects of the informational needs in the conservation and management of water resources, as well as in post-event damage assessment and recovery planning.

The OGC has developed several OS for the storage and sharing of geospatial data, including data in the water domain, and for the publishing and processing of this data over the Web. Several interoperability experiments have advanced the knowledge of the specifications and procedures necessary to make data and systems interoperable. Today there are mature and well-tested FOSS alternatives for the creation of robust and reliable Web mapping systems. We suggest that FOSS offer features and capabilities that can complement, and in some cases be superior, to their proprietary software counterparts for the development of the next generation of Web mapping systems in the water domain.

The next-generation geospatial platforms in the water domain should focus on the use of: 1) data specifications to store and share water-related data with the appropriate semantics, 2) interface standards to access wireless real-time sensor networks (e.g. using the Open Geospatial Consortium Sensor Observation Service (SOS) specification), 3) Web Processing Services (WPS) for migrating geospatial data processing and modeling processes from desktop GIS systems to the Web, 4) technologies that have low access costs and facilitate the creation of flexible, interoperable Web-based systems, and 5) need-oriented services designed according to real users' requirements.

This type of systems would have been extremely complicated to develop even a few years ago. OS and FOSS technologies have lowered the knowledge and effort necessary to develop such systems. This is extremely valuable given that many scientists, agencies, and governments around the world don't have access to ample and sophisticated resources for the creation of their Web mapping system in the water domain. However, there is a need to educate managers and IT professionals on the features, advantages, and ways to use the FOSS and OS relevant for the creation of interoperable Web-based applications.

The use of FOSS does not require an initial software cost, which facilitates testing and prototyping new systems based on system architectures such as the ones proposed here. This activity can be a low-cost educational opportunity for IT personnel in water agencies around the world. Also, in doing so, these agencies do not have to commit to a proprietary solution that would divert financial resources from their current IT solutions and commitments. Previous experiences suggest that an architecture based on the use of FOSS is more likely to be agreeable among agencies with diverse levels of funding, personnel expertise and development of their IT infrastructures (Moreno-Sanchez et al. 2007). Finally, the openness, distributed development, spirit of cooperation, and willingness to contribute back to the community under which FOSS and OS are developed can facilitate and encourage a spirit of cooperation between agencies and countries for the creation of the next-generation of Web mapping systems in the water domain.

\section{ACKNOWLEDGEMENTS}

The authors wish to acknowledge Simone Corti for his technical support and the communities behind the free and open source software used in the three use cases.

\section{REFERENCES}

Al-Najar, H., 2011. The integration of FAO-CropWat Model and GIS Techniques for Estimating Irrigation Water Requirement and Its Application in the Gaza Strip. Natural Resources, 2(3), pp. 146-154.

Auynirundronkool, K., Chen, N., Peng, C., Yang, C., Gong, J., Silapathong, C., 2012. Flood detection and mapping of the Thailand Central plain using RADARSAT and MODIS under a sensor web environment. International Journal of Applied Earth Observation and Geoinformation, 14(1), pp. 245-255.

Bonaccorsi, A., Rossi, C., 2003. Why open source software can succeed. Research Policy 32(7), pp. 1243-1258.

Brovelli, M. A., Kilsedar, C. E., Minghini, M., Oxoli, D., 2016. GIS-based analysis of a peculiar effect of urbanization: the case of the buried watercourses of Como (Italy). Applied Geomatics, 8(2), pp. 91-105.

Díaz, L., Costa, S., Granell, C., Gould, M., 2007. Migrating geoprocessing routines to web services for water resource management applications. 10th AGILE Conference on Geographic Information Science, Aalborg, Denmark.Bodum, Lars Agil.

DiBona, C., Ockman, S., 1999. Open sources: Voices from the Open Source Revolution. O’Reilly Media, Inc.

Feng, M., Liu, S., Euliss Jr, N. H., Young, C., Mushet, D. M., 2011. Prototyping an online wetland ecosystem services model using open model sharing standards. Environmental Modelling \& Software, 26(4), pp. 458-468.

Feng, Z., Liu, D., Zhang, Y., 2007. Water requirements and irrigation scheduling of spring maize using GIS and CropWat model in Beijing-Tianjin-Hebei region. Chinese Geographical Science, 17(1), pp. 56-63.

Giupponi, C., 2007. Decision Support Systems for implementing the European Water Framework Directive: The MULINO approach. Environmental Modelling \& Software, 22(2), pp. 248258. 
Giupponi, C., Vladimirova, I., 2006. Ag-PIE: A GIS-based screening model for assessing agricultural pressures and impacts on water quality on a European scale. Science of The Total Environment, 359(1-3), pp. 57-75.

Johnson, L. E., 2008. Geographic Information Systems in Water Resources Engineering. Taylor \& Francis Group.

Johnson, R., 2000. GIS technology for disasters and emergency management. An ESRI White Papper.

Jorgensen, S. E., Loffler, H., Rast, W., Straskraba, M., 2005. Lake and Reservoir Management, Volume 54, $1^{\text {st }}$ Edition. Access online via Elsevier.

Labadie, J. W., 2004. Optimal Operation of Multireservoir Systems: State-of-the-Art Review. Journal of Water Resources Planning and Management, 130(2), pp. 93-111.

Lagesse, D., 2002. Out the windows: Breaking with Microsoft gets a little easier. U.S. News \& World Report.

Lanig, S., Schilling, A., Stollberg, B., Zipf, A., 2008. Towards Standards-Based Processing of Digital Elevation Models for Grid Computing through Web Processing Service (WPS). Computational Science and Its Applications - ICCSA 2008, pp. 191-203.

Loucks, D. P., Van Beek, E., Stedinger, J. R., Dijkman, J. P. M., Villars, M. T., 2005. Water Resources Systems Planning and Management: An Introduction to Methods, Models and Applications. Paris, UNESCO.

Merz, B., Kreibich, H., Schwarze, R., Thieken, A., 2010. Review article "Assessment of economic flood damage". Natural Hazards Earth System Sciences, 10(8), pp. 1697-1724. doi:10.5194/nhess-10-1697-2010

Moreno-Sanchez, R., 2006. Distributed GIS Systems, Open Specifications and Interoperability: How do They Relate to the Sustainable Management of Natural Resources?

Moreno-Sanchez, R., Anderson, G., Cruz, J., Hayden, M., 2007. The potential for the use of Open Source Software and Open Specifications in creating Web-based cross-border health spatial information systems. International Journal of Geographical Information Science, 21(10), pp. 1135-1163.

Müller, M., Bernard, L., Brauner, J., 2010. Moving Code in Spatial Data Infrastructures - Web Service Based Deployment of Geoprocessing Algorithms. Transactions in GIS, 14(s1), pp. 101118.

Mysiak, J., Giupponi, C., Rosato, P., 2005. Towards the development of a decision support system for water resource management. Environmental Modelling \& Software, 20(2), pp. 203-214.

Prins, J., Bodeaux, M., 2000. GIS in Education: Across Campuses, Inside Facilities. Building Land Use Plans for Water and Irrigation Master Plans: A Case Study. San Diego, California.

Ramos, M.-H., Bartholmes, J., Thielen-del Pozo, J., 2007. Development of decision support products based on ensemble forecasts in the European flood alert system. Atmospheric Science Letters, 8(4), pp. 113-119. doi:10.1002/asl.161
Raymond, E. S., Young, B., 2001. The Cathedral \& the Bazaar: Musings on Linux and Open Source by an Accidental Revolutionary.

Shekhar, S., Xiong, H., 2008. Encyclopedia of GIS. Springer US.

Soncini-Sessa, R., Weber, E., Castelletti, A., 2007. Integrated and Participatory Water Resources Management - Theory. Elsevier.

Thielen, J., Bartholmes, J., Ramos, M.-H., Roo, A. de, 2009. The European Flood Alert System - Part 1: Concept and development. Hydrology and Earth System Sciences, 13(2), pp. 125-140. https://doi.org/10.5194/hess-13-125-2009

Todorovic, M., Steduto, P., 2003. A GIS for irrigation management. Physics and Chemistry of the Earth, Parts $A / B / C$, 28(4-5), pp. 163-174.

Vanrolleghem, P. A., 2011. Decision Support for Water Framework Directive Implementation. IWA Publishing.

Vogt, J., 2002. Implementing the GIS Elements of the Water Framework Directive.

Walenciak, G., Stollberg, B., Neubauer, S., Zipf, A., 2009. Extending Spatial Data Infrastructures 3D by Geoprocessing Functionality - 3D Simulations in Disaster Management and environmental Research. Advanced Geographic Information Systems \& Web Services, 2009, pp. 40-44. doi:10.1109/GEOWS.2009.16

Wriedt, G., Van der Velde, M., Aloe, A., Bouraoui, F., 2009. Estimating irrigation water requirements in Europe. Journal of Hydrology, 373(3-4), pp. 527-544.

Wu, Z., Wang, R., Diaz, D., and Walski, T., 2003. Mining Water Consumption and GIS-Based Data for Loading Water Distribution Models. World Water \& Environmental Resources Congress, Philadelphia, Pennsylvania, United States. doi:10.1061/40685

Zerger, A., 2002. Examining GIS decision utility for natural hazard risk modelling. Environmental Modelling \& Software, 17(3), pp. 287-294. https://doi.org/10.1016/S13648152(01)00071-8

Zerger, A., Smith, D. I., 2003. Impediments to using GIS for realtime disaster decision support. Computers, Environment and Urban Systems, 27(2), pp. 123-141. https://doi.org/10.1016/S0198-9715(01)00021-7

Zerger, A., Wealands, S., 2004. Beyond Modelling: Linking Models with GIS for Flood Risk Management. Natural Hazards, 33(2), pp. 191-208. 